\title{
Serum level of vitamin D, CRP and biochemical parameter in acute and chronic brucellosis treated with doxycycline-loaded solid lipid nanoparticles
}

\section{Seyed Mostafa Hosserini}

Hamadan University of Medical Sciences Medical School

Abbas Farmani

Dental Research Center, Hamadan University of Medical Science

Mohammad Reza Arabestani ( $D$ mr_arabestani@yahoo.com )

Hamadan University of Medical Sciences Medical School https://orcid.org/0000-0001-9991-8193

Research article

Keywords: Brucellosis, nanoparticles, Vitamin D, CRP, total protein

Posted Date: November 7th, 2019

DOl: https://doi.org/10.21203/rs.2.16915/v1

License: (c) (i) This work is licensed under a Creative Commons Attribution 4.0 International License.

Read Full License 


\section{Abstract}

Background Brucellosis is a common disease between humans and livestock, and treatment and relapse of this disease is one of the major challenges. The aim of this study was to evaluate the therapeutic effect of doxycycline-loaded solid lipid nanoparticles (DOX-SLN) on acute and chronic brucellosis and its effect on serum level of $25-\mathrm{OH}$-Vitamin D, C-reactive protein (CRP) and biochemical parameters.

Methods Double emulsion method was used for synthesis of nanoparticles. Serum levels of vitamin D, CRP, total protein, albumin and globulin were measured in rats with brucellosis. The therapeutic effect of DOX-SLN was compared with that of free doxycycline.

Results The mean size, Zeta potential, PDI, drug loading and encapsulation efficiency of the synthesized nanoparticles were $299 \pm 34 \mathrm{~nm},-28.7 \pm 3.2 \mathrm{mV}, 0.29 \pm 0.027,11.2 \pm 1.3 \%$, and $94.9 \pm 3.2 \%$, respectively. Serum vitamin $\mathrm{D}$ levels in rats with chronic brucellosis decreased compared to healthy rats. CRP increased in the acute and chronic stages of brucellosis. Serum levels of total protein and albumin were similar in both stages of the disease but serum globulin levels was increased.

Conclusion According to the results, serum level of vitamin D was increased in rats after treatment with DOX-SLN. The use of DOX-SLN as an alternative drug for the treatment of chronic brucellosis is recommended.

\section{Background}

Brucella is a facultative intracellular coccobacilli, spore-free, capsule-free and nonmotile gram-negative bacillus of various types and, at least, four of them are pathogenic in humans, including Brucella melitensis, Brucella abortus, Brucella suis and Brucella canis [1].

Because of the high ability of Brucella bacteria to survive and hide within cells after treatment, relapse of brucellosis will occur after a few months due to a weakened immune system [2]. Most relapse occur within the first six months after treatment with clinical findings milder than the initial course of the disease, although some patients, in particular, show mild clinical relapse [2]. It should be noted that the mechanism of host immune response to brucellosis may be varied, depending on the host and strains of Brucella. The goal of any treatment for brucellosis in humans is to fight the symptoms, reduce the complications and ultimately prevent its relapse. Since, it is difficult to completely eradicate the microorganism, antibiotic compounds are prescribed to produce a long-term synergistic effect $[3,4]$.

Low stability in the intracellular environment or degradation by lysosomal enzymes results in the inefficiency of antibiotics administered against intracellular microorganisms. However, the wide distribution of these drugs does not reach the organism fully and its presence in non-infectious tissues apart from their intrinsic toxicity may lead to adverse effects [5]. 
Despite the emergence of a significant number of new antibiotics, the treatment of intracellular pathogens still represents a challenge in pharmacy [6]. Nowadays, with the preparation of pharmaceutical nanoparticles, unique properties can be achieved that will increase the performance and variety of its drug forms. Accurate formulation of nanoparticles results in their higher stability and can increase the rate of dissolution and reaches biological levels, which will accelerate their therapeutic effect and improve their bioavailability $[7,8]$.

At this time, the need to develop drug delivery systems that can overcome these problems seems very urgent. These carrier systems should be non-toxic, capable of accepting sufficient amounts of drug, and in addition capable of targeting and controlling drug release [9]. Solid lipid nanoparticles as a carrier system have been investigated for many applications. Many drugs have been successfully incorporated into the SLN with a variety of uses. These drug delivery systems controls the release of drugs and increase the chemical stability of drugs[10,11].

Regardless of the role of vitamin D in calcium homeostasis, it has an essential role in the innate and acquired immune system. This effect is exerted by vitamin $D$ receptors on many immune cells $[12,13]$. This vitamin has the role of regulating the level of immunity and serum levels of this micronutrient affect the susceptibility and outcome of many infections. There is ample laboratory evidence of a correlation between serum vitamin D levels and the risk of infectious diseases. Vitamin D has been shown to increase phagocytosis of macrophages and increase the production of cathelicidin antimicrobial peptide and accelerate killing of intracellular bacteria. On the other hand, the INF1-dependent antimicrobial pathway in human macrophages is associated with appropriate serum levels of vitamin $D[14,15]$.

Due to the fact that brucellosis affects the vital organs of the body, including the liver, spleen, joints, etc., their function is impaired and increases or decreases various enzymes and proteins in the body[16]. In some studies, using electrophoresis of proteins in the serum, serum levels of proteins change during infectious diseases that are associated with long-term inflammation. C-reactive proteins are acute phase reactants. In $99 \%$ of healthy adults, the concentration of CRP in the serum is less than $1 \mathrm{mg} / \mathrm{L}$. The rapid increase in CRP is observed in most infectious diseases[17].

The aim of this study was to evaluate the therapeutic effect of doxycycline-loaded solid lipid nanoparticles (SLN) on acute and chronic brucellosis and its effect on serum levels of vitamin D, CRP and proteins in in vivo condition.

\section{Methods}

\section{Infection of rats and treatment with drugs and nanoparticles}

The nanoparticles used in this study are SLNs loaded with doxycycline (DOX-SLN) which was previousely synthesized by Double Emulsion Method [18]. Size, zeta potential and PDI of nanoparticles were determined. Drug loading and encapsulation were evaluated by HPLC. Drug release and drug stability, up 
to 1 year after synthesis, were evaluated. FTIR, DSC and FESEM microscopy methods were used to confirm the chemical and physical properties of the synthesized nanoparticle [18].

Male Wistar rats with an age ranged from 6 to 8 weeks and $250( \pm 30) \mathrm{g}$ weight were purchased from the breeding center of the animal facility of Hamadan University of medical sciences.

Rats were infected by intraperitoneal injection of $1.5 \times 10^{6} \mathrm{CFUs}$ of $B$. melitensis. After 10 days of infection (acute stage of infection) and 5 weeks of infection (chronic stage of infection), the rats were divided into 4 groups [19]. For performing the acute stage; the rats were infected ten days, one group of rats was kept untreated as positive controls and the other two groups (five rats per group) were treated with three different doses of (1) free doxycycline (2.5 mg/kg), (2) DOX-SLN (2.5 mg/kg) at days 11, 13 and 15 post infection and healthy rat [20].

For performing chronic stage; the rats were infected for 5 weeks, no treatment was conducted on one group and the rats in this group were regarded as positive controls, while the other two groups (ten rats per group) were treated with ten doses of (1) free doxycycline (2.5 mg/kg), (2) DOX-SLN (2.5 mg/kg) for 10 days (once daily) and healthy rat [20].

After the second day of the last dose, rats were anesthetized and blood samples were taken from $10 \mathrm{cc}$ syringes. $\mathrm{CBC}$ and serum and plasma samples were prepared for subsequent tests.

\section{Ethics statement}

All experiments involving animals were performed according to the guidelines for maintenance, surveillance and usage of laboratory animals published by the National Institute of Health United State (NIH publication No.85-23, revised 1985). Moreover, the study was approved by the ethics committee of the Hamadan University of Medical Sciences (No: IRUMSHA. REC. 1395066). In order to be adopted to the new environment, all rats were transported to the laboratory one week before the beginning of examinations. All operations able to induce anxious and pain in rats were performed in another room separated from where rats were kept. Rats were anesthetized using a mixture of ketamine $(100 \mathrm{mg} / \mathrm{kg})$ and xylazine $(10 \mathrm{mg} / \mathrm{kg})$, then, the liver and spleen tissues and whole blood sample were taken from them. At the end of the study, rats were sacrificed with a specialized rodent guillotine and animal carcasses were disposed in a lime pit.

\section{Serum level of vitamin D}

25-OH-Vitamin D Elisa kit (PGI-IRAN) was used to determine serum level of vitamin D, the procedure was performed according to the kit protocol [21].

\section{Serum CRP level}

NycoCard (Norway) kits were used to determine the CRP levels in rats of different study groups. Immunochemical assay was used for the quantitative determination of CRP in serum of different rats 
[22].

\section{Serum levels of total protein, albumin, and globulin}

After serum isolation from blood samples, the levels of total protein, albumin and globulin were determined using the audit kit (Ireland) and automatic analyzer (Hitachi 911, Japan) with photometry method [7].

\section{Statistical analysis}

The mean \pm standard deviations of serum level of vitamin D, CRP, total protein, albumin and globulin in acute and chronic stage of brucellosis were determined. The analysis of variance (ANOVA) and Duncan's multiple range test were used to compare the positive control group with experimental groups. Pearson's correlation analysis was used to obtain the relationships between the parameters examined in the groups. The confidence level was regarded as $95 \%$ and $P<0.05$ which was considered statistically significant.

\section{Results}

\section{DOX-SLN characteristics}

The mean size, Zeta potential, PDI, drug loading and encapsulation efficiency of the synthesized nanoparticles are as $299 \pm 34 \mathrm{~nm},-28.7 \pm 3.2 \mathrm{mV}, 0.29 \pm 0.027,11.2 \pm 1.3 \%$, and $94.9 \pm 3.2 \%$, respectively.

\section{Serum vitamin D levels}

Serum vitamin D levels in the control group were significantly lower than the control group $(P<0.05)$, but this difference was not statistically significant $(P>0.05)$. At this stage, treatment with rats using free doxycycline and DOX-SLN did not increase their vitamin D levels and did not reach negative control levels. At the chronic stage of disease, the decrease in serum vitamin $D$ level in the positive control group was statistically significant compared to the negative control group. $(P=0.04)$. There was no significant difference in the doxycycline and DOX-SLN treated rats (Figure 1, Table 1, 2).

\section{Serum CRP level}

CRP was increased in both acute and chronic stages in the positive control group. $(P=0.001)$. Treatment of rats using free doxycycline and DOX-SLN in both acute and chronic stages reduced CRP compared to the positive control group, although this decrease was not statistically significant. In the DOX-SLN recipient group, CRP levels were lower in the chronic stage of brucellosis than in the free doxycycline recipient group (Figure 2). Since healthy rats had a CRP of less than 3 , there was a significant difference between the serum CRP level and rats with brucellosis $(P=0.000)$. 


\section{Serum level of total protein, Alb and globulin}

Serum total protein level in the positive control group rats was not significantly different from that in the negative control group ( $p>0.05$ ). In the acute phase of the disease, total protein increased $0.5 \mathrm{~g} / \mathrm{dl}$ in the positive control group compared to the negative control group. In the rats treated with free doxycycline and DOX-SLN, there was no difference in serum total protein level (Figure. 3). No difference in the serum albumin levels was observed in the acute and chronic groups (Fig. 4). Serum globulin level in the positive control group rats was equal to $1.1 \mathrm{~g} / \mathrm{dl}$ compared to the negative control group rats $(p=0.001)$. In the acute phase of brucellosis, the serum globulin level of DOX-SLN-treated rats was lower than the positive control group, but there was no difference in the serum levels of globulin with the free doxycycline-treated rats. In the chronic phase of the disease, elevated serum globulin levels were also observed in untreated (positive control) rats compared to the negative control rats (Figure. 5).

\section{Discussion}

Chronic infections such as brucellosis impose a heavy economic burden on the society [23]. Intracellular bacteria are protected from antibodies, complement and some antibiotics when they are inside the cells, as well as new physicochemical conditions within the cells induce strategic (structural and metabolic) changes in the bacteria that cause resistance to antibiotics [24]. Antibiotic activity may change due to the acidic conditions of the phagosomes as well as the lack of antibiotics access to the organelles within the cells, so the final antibiotic exposure to the pathogens may not occur. For this reason, the need for antibiotic-containing nanoparticles that can be modified under these conditions and remain for a longer time and slowly and continuously targeting the target organ and microorganism of drug delivery $[25,26]$. The aim of this study was to evaluate the therapeutic effect of DOX-SLN on acute and chronic brucellosis and to determine the effect of nanoparticle on serum levels of vitamin D, CRP, total protein, albumin and globulin in healthy and brucellosis rats treated with free doxycycline and DOX-SLN.

In the present study, serum levels of vitamin $D$ in the acute phase were reduced in the positive control (untreated rats) compared to the negative control (healthy rats). Kurtaran and colleagues investigated the association between serum level of vitamin $D$ and brucellosis [27]. Their results showed that in patients with brucellosis, the serum level of vitamin D was $23.3 \mathrm{ng} / \mathrm{ml}$, which was $6.9 \mathrm{ng} / \mathrm{ml}$ on average lower than healthy subjects. They concluded that brucellosis causes a decrease in the serum level of vitamin $D$.

Gharebaghi et al. compared serum levels of vitamin D in patients with tuberculosis (caused by Mycobacterium tuberculosis, an intracellular bacterium) compared to healthy controls [28]. Their results showed that the serum level of vitamin $D$ in the patient group was $15.07 \mathrm{ng} / \mathrm{dL}$ significantly lower than the serum level of vitamin $D$ in the control group (healthy subjects) with $16.88 \mathrm{ng} / \mathrm{dL}$, which is consistent with our study. Also, Ataei et al. examined the serum levels of vitamin D in people with hepatitis C [29]. Their results showed that in healthy subjects the serum level of vitamin D was $29.6 \mathrm{ng} / \mathrm{dl}$ and in patients was $26.23 \mathrm{ng} / \mathrm{dL}$ which is similar to the results of this study. 
Based on the current knowledge of vitamin D metabolism, there are many reasons for the very high prevalence of vitamin D deficiency in patients with chronic liver disease and cirrhosis. One of the causes of vitamin D deficiency in chronic hepatic patients is hepatic hydroxylation and extra hepatic increase in vitamin D uptake. It is clear that many patients with chronic liver disease and cirrhosis have inadequate levels of serum vitamin D [30].

In the present study, elevated serum levels of vitamin D were observed after treatment with DOX-SLN in the chronic stage of the disease. This provides a good therapeutic effect of DOX-SLN compared to free doxycycline. Since nanoparticles consistently release the drug in the bacterial site, and as liver tissue improves after treatment with DOX-SLN, vitamin D levels increase in the serum of rats.

In the present study, serum CRP levels were increased in both acute and chronic stages in the positive control group compared with the negative control group. Navarro and his colleagues measured the CRP levels before and after brucellosis treatment [31]. Their findings showed that CRP measurement is a very good indicator for the diagnosis of brucellosis, as the changes in CRP before and after treatment were quite significant, which is consistent with our study. Demirdag et al., examined the serum levels of acute phase proteins and cytokines in patients with brucellosis [32]. Their findings showed that in patients with acute brucellosis, the serum level was $52.5 \mathrm{CRP}$, which decreased to $11 \mathrm{mg} / \mathrm{L}$ after treatment. Their findings showed a correlation between serum levels of INF-1 and TNF- $a$ with serum levels of CRP. CRP is a specific type of protein produced in the liver that occurs during the course of acute inflammation of infections.

Evaluation of serum protein levels in rats with brucellosis showed that serum total protein level in the positive control group rats was not different from the negative control in the chronic phase of Brucellosis. No significant difference was observed in serum levels of albumin in different treatment groups in acute and chronic stages. But the serum level of globulin was increased in the diseased rats. Całkosiński, and his colleagues conducted a study on Pleurisy, an inflammatory disease [33]. The results of serum levels of proteins in the acute phase of the disease and at specific intervals showed that serum albumin levels decreased during the course of the disease, while serum levels of globulin increased. As well as total serum protein levels were constant, this finding is consistent with our results. According to the results of this study, vitamin D decreased in brucellosis patients and increased CRP and globulin. DOX-SLN has an acceptable therapeutic effect as an alternative to the brucellosis treatment compared to free doxycycline, increasing serum levels of vitamin D and lowering CRP and globulin in the chronic phase of the disease. Therefore, application and use of nanoparticles can lead to better treatment and decrease the relapse of brucellosis.

\section{Abbreviation}

CRP: C-reactive protein; SLN: Solid Lipid Nanoparticles; DOX-SLN: Doxycycline-loaded Solid Lipid Nanoparticles; PDI: Polydispersity index; FTIR: Fourier-transform infrared spectroscopy; DSC: Differential 
scanning calorimetry; NPs: Nanoparticles; FE-SEM: Field emission scanning electronic microscope; HPLC: high-performance liquid chromatography.

\section{Declarations}

\section{Ethics approval and consent to participate}

This study was approved by the ethics committee of Hamadan University of Medical Sciences (No: IRUMSHA. REC. 1395066)

\section{Consent for publication}

Not applicable

\section{Availability of data and materials}

The data can be accessible to the interested researchers by the corresponding authors on reasonable request.

\section{Competing interests}

The authors declare no competing interests.

\section{Funding}

This study has been adapted from a PhD. thesis at Hamadan University of Medical Sciences (Project No. 9510146066).

\section{Authors' contributions}

SMH and MA designed the study. SMH contributed in the experimental studies, and drafting the work. $\mathrm{SMH}$ and $\mathrm{AF}$ performed the analysis of the data. $\mathrm{SMH}, \mathrm{MA}$ contributed in the animal study. $\mathrm{SMH}$ and $\mathrm{AF}$ designed the nanoparticles. All authors read and approved the final manuscript.

\section{Acknowledgments}

The authors would like to acknowledge the Vice Chancellor of Hamadan University of Medical Sciences for the funding and support of the study and Hamedan Science, Kasra pathobiology laboratory and Technology Park.

\section{Authors' Information}

Seyed Mostafa Hosseini, PhD. in Medical Microbiology, Microbiology department, School of Medicine, Hamadan University of Medical Sciences, Hamadan, Iran, Abbas Farmany, Assistance Professor in Nanobiotechnology, Dental Research Center, School of Dentistry, Hamadan University of Medical 
Sciences, Hamadan, Iran, Mohammad Reza Arabestani, Associate Professor in Medical Bacteriology, Microbiology department, School of Medicine, Hamadan University of Medical Sciences, Hamadan, Iran

\section{References}

1. de Figueiredo P, Ficht TA, Rice-Ficht A, Rossetti CA, Adams LG (2015) Pathogenesis and immunobiology of brucellosis: review of Brucella-Host Interactions. The American journal of pathology 185 (6):1505-1517

2. Mohammed HA (2018) Brucellosis Relapse: A Retrospective Study of Risk Factors among Saudi Patients. Afro-Egyptian Journal of Infectious and Endemic Diseases 8 (3):149-154

3. Alizadeh M, Safarzadeh A, Bahmani M, Beyranvand F, Mohammadi M, Azarbaijani K, Rafieian-Kopaei M, Abbaszadeh S (2018) Brucellosis: Pathophysiology and new promising treatments with medicinal plants and natural antioxidants. Asian Pacific Journal of Tropical Medicine 11 (11):597

4. Roushan MRH, Ebrahimpour S (2015) Human brucellosis: An overview. Caspian journal of internal medicine 6 (1):46

5. Mu H, Tang J, Liu Q, Sun C, Wang T, Duan J (2016) Potent antibacterial nanoparticles against biofilm and intracellular bacteria. Scientific reports 6:18877

6. Ntirandekura J-B, Matemba LE, Ngowi HA, Kimera SI, Karimuribo ED (2018) Knowledge, perceptions and practices regarding brucellosis in pastoral communities of Kagera Region in Tanzania. Journal of Advanced Veterinary and Animal Research 5 (3):343-353

7. Hosseini SM, Farmany A, Arabestani MR (2019) Effect of Doxycycline-Loaded Solid Lipid Nanoparticles on Serum Level of Trace Elements, Biochemical and Hematological Parameters in Acute and Chronic Brucellosis. Biological trace element research:1-9

8. Ghaderkhani J, Yousefimashouf R, Arabestani M, Roshanaei G, AsI SS, Abbasalipourkabir R (2019) Improved antibacterial function of Rifampicin-loaded solid lipid nanoparticles on Brucella abortus. Artificial cells, nanomedicine, and biotechnology 47 (1):1181-1193

9. Moeinpour F, Soofivand F, Mohseni-Shahri FS (2019) Controlled release of losartan from acid-and heat-treated halloysite nanotubes. Medicinal Chemistry Research 28 (2):160-168

10. Geszke-Moritz M, Moritz M (2016) Solid lipid nanoparticles as attractive drug vehicles: Composition, properties and therapeutic strategies. Materials Science and Engineering: C 68:982-994

11. García E, Ochoa R, Vásquez I, Conesa-Milián L, Carda M, Yepes A, Vélez ID, Robledo SM, Cardona-G W (2019) Furanchalcone-biphenyl hybrids: synthesis, in silico studies, antitrypanosomal and cytotoxic activities. Medicinal Chemistry Research 28 (4):608-622

12. Abdel-Hafez SH, Gobouri AA, Alshanbari NA, El-Rab SMG (2018) Synthesis of novel vitamin E containing sulfa drug derivatives and study their antibacterial activity. Medicinal Chemistry Research 27 (10):2341-2352

13. Veldurthy V, Wei R, Oz L, Dhawan P, Jeon YH, Christakos S (2016) Vitamin D, calcium homeostasis and aging. Bone research 4:16041 
14. Clark A, Mach N (2016) Role of vitamin D in the hygiene hypothesis: the interplay between vitamin $D$, vitamin $D$ receptors, gut microbiota, and immune response. Frontiers in immunology 7:627

15. Song M, Nishihara R, Wang M, Chan AT, Qian ZR, Inamura K, Zhang X, Ng K, Kim SA, Mima K (2016) Plasma 25-hydroxyvitamin $D$ and colorectal cancer risk according to tumour immunity Gut 65 (2):296-304

16. Balın ŞÖ, Tartar AS, Akbulut A (2018) The predictive role of haematological parameters in the diagnosis of osteoarticular brucellosis. African health sciences 18 (4):988-994

17. Hashemi SH, Esna-Ashari F, Nemat Gorgani F, Tayebinia H, Mamani M (2018) Increased serum levels of hepcidin and C-reactive protein in patients with brucellosis. Transactions of The Royal Society of Tropical Medicine and Hygiene 112 (11):509-512

18. Hosseini SM, Abbasalipourkabir R, Jalilian FA, Asl SS, Farmany A, Roshanaei G, Arabestani MR (2019) Doxycycline-encapsulated solid lipid nanoparticles as promising tool against Brucella melitensis enclosed in macrophage: a pharmacodynamics study on J774A. 1 cell line. Antimicrobial Resistance \& Infection Control 8 (1):62

19. Jain-Gupta N, Pothayee N, Pothayee N, Tyler R, Caudell DL, Balasubramaniam S, Hu N, Davis RM, Riffle JS, Sriranganathan N (2013) Efficacies of gentamicin-loaded magnetite block ionomer complexes against chronic Brucella melitensis infection. Journal of nanoparticle research 15 (11):2024

20. Imbuluzqueta E, Gamazo C, Lana H, Campanero MÁ, Salas D, Gil AG, Elizondo E, Ventosa N, Veciana J, Blanco-Prieto MJ (2013) Hydrophobic gentamicin-loaded nanoparticles are effective against Brucella melitensis infection in mice. Antimicrobial agents and chemotherapy 57 (7):3326-3333

21. Lee S, Oncescu V, Mancuso M, Mehta S, Erickson D (2014) A smartphone platform for the quantification of vitamin D levels. Lab on a Chip 14 (8):1437-1442

22. Sundrehagen E (2019) Kit for a Determination Method for Calprotectin and the Use of Calprotectin as a Predictive Marker for Cardiovascular Disease. Google Patents,

23. Cascio A, Bosilkovski M, Rodriguez-Morales A, Pappas G (2011) The socio-ecology of zoonotic infections. Clinical microbiology and infection 17 (3):336-342

24. Martínez JL, Baquero F (2002) Interactions among strategies associated with bacterial infection: pathogenicity, epidemicity, and antibiotic resistance. Clinical microbiology reviews 15 (4):647-679

25. Singh R, Lillard Jr JW (2009) Nanoparticle-based targeted drug delivery. Experimental and molecular pathology 86 (3):215-223

26. Blanco E, Shen H, Ferrari M (2015) Principles of nanoparticle design for overcoming biological barriers to drug delivery. Nature biotechnology 33 (9):941

27. Kurtaran B, Akyildiz O, Ulu AC, Inal SA, Komur S, Seydaoglu G, Arslan YK, Yaman A, Kibar F, Aksu HSZ (2016) The relationship between brucellosis and vitamin D. The Journal of Infection in Developing Countries 10 (02):176-182

28. Gharebaghi N, Nikoonejad A (2017) Study of serum levels of vitamin d, calcium and Parathyroid hormone in patient with tuberculosis And comparison with control group (a case control Study). The 
Journal of Urmia University of Medical Sciences 27 (11):26-30

29. ATAEI B, AKHGAVAN GZ, KHORVASH F, ATAEI A (2016) Serum levels of 25-hydroxy vitamin D in patients with hepatitis $C$ compared with control group.

30. Beltrân M, Navas M-C, De la Hoz F, Muñoz MM, Jaramillo S, Estrada C, del Pilar Cortés L, Arbelâez MP, Donado J, Barco G (2005) Hepatitis C virus seroprevalence in multi-transfused patients in Colombia. Journal of clinical virology 34:S33-S38

31. Navarro J, Mendoza J, Leiva J, Rodriguez-Contreras R, de la Rosa M (1990) C-reactive protein as a prognostic indicator in acute brucellosis. Diagnostic microbiology and infectious disease 13 (3):269270

32. Demirdag K, Ozden M, Kalkan A, Godekmerdan A, Kilic SS (2003) Serum cytokine levels in patients with acute brucellosis and their relation to the traditional inflammatory markers. FEMS Immunology \& Medical Microbiology 39 (2):149-153

33. Całkosiński I, Rosińczuk-Tonderys J, Bazan J, Dzierzba K, Całkosińska M, Majda J, Dobrzyński M, Bronowicka-Szydetko A (2013) The influence of 2, 3, 7, 8-tetrachlorodibenzo-p-dioxin (TCDD) on hematological parameters during experimentally induced pleuritis in rats. Inflammation 36 (2):387404

\section{Tables}

Table 1: Comparison of vitamin $\mathrm{D}$, total protein, albumin, globulin and CRP between different groups of rat in acute brucellosis

\begin{tabular}{l|l|l|l|l|l|}
\hline ap/parameter & $\begin{array}{l}\text { Vitamin D } \\
(\mathrm{ng} / \mathrm{mL})\end{array}$ & $\begin{array}{l}\text { Total protein } \\
(\mathrm{g} / \mathrm{dL})\end{array}$ & $\begin{array}{l}\text { Albumin } \\
(\mathrm{g} / \mathrm{dL})\end{array}$ & $\begin{array}{l}\text { Globulin } \\
(\mathrm{g} / \mathrm{dL})\end{array}$ & $\begin{array}{l}\text { CRP } \\
(\mathrm{mg} / \mathrm{L})\end{array}$ \\
\hline tive control & $25.6 \pm 2.2$ & $7 \pm 0.1$ & $2.9 \pm 0.1^{*}$ & $\begin{array}{l}2.5 \pm \\
0.07^{* *}\end{array}$ & $\begin{array}{l}15.3 \pm \\
1.2^{* *}\end{array}$ \\
\hline : doxycycline & $26.7 \pm 3.1$ & $6.7 \pm 0.1$ & $3 \pm 0.08$ & $2.4 \pm 0.1^{*}$ & $\begin{array}{l}13.7 \pm \\
0.9^{* *}\end{array}$ \\
\hline -SLN & $27.5 \pm 1.2$ & $6.5 \pm 0.09$ & $2.9 \pm 0.1$ & $2 \pm 0.1^{*}$ & $\begin{array}{l}13.9 \pm \\
1.13^{* *}\end{array}$ \\
\hline
\end{tabular}

Table 2: Comparison of vitamin $\mathrm{D}$, total protein, albumin, globulin and CRP between different groups of rat in chronic brucellosis 


\begin{tabular}{|c|c|c|c|c|c|}
\hline iup/parameter & $\begin{array}{l}\text { Vitamin D } \\
\text { (ng/mL) }\end{array}$ & $\begin{array}{l}\text { Total protein } \\
(\mathrm{g} / \mathrm{dL})\end{array}$ & $\begin{array}{l}\text { Albumin } \\
\text { (g/dL) }\end{array}$ & $\begin{array}{l}\text { Globulin } \\
\text { (g/dL) }\end{array}$ & $\begin{array}{l}\text { CRP } \\
(\mathrm{mg} / \mathrm{L})\end{array}$ \\
\hline itive control & $18.1 \pm 1.9 *$ & $6.6 \pm 0.2$ & $3.0 \pm 0.09$ & $2.4 \pm 0.1^{* *}$ & $\begin{array}{l}10.1 \pm \\
0.9^{* *}\end{array}$ \\
\hline e doxycycline & $20.4 \pm 2.9$ & $6.5 \pm 0.1$ & $3.1 \pm 0.1$ & $2.1 \pm 0.09 *$ & $\begin{array}{l}9.2 \pm \\
1.1 * *\end{array}$ \\
\hline$\overline{\mathrm{X}-\mathrm{SLN}}$ & $22.1 \pm 0.9$ & $6.4 \pm 0.2$ & $3 . .3 \pm 0.3$ & $1.8 \pm 0.2^{*}$ & $\begin{array}{l}4.1 \pm \\
1.6^{* *}\end{array}$ \\
\hline ative control & $29.6 \pm 2.1$ & $6.5 \pm 0.09$ & $3.4 \pm 0.2$ & $1.5 \pm 0.1$ & 0.00 \\
\hline
\end{tabular}

\section{Figures}

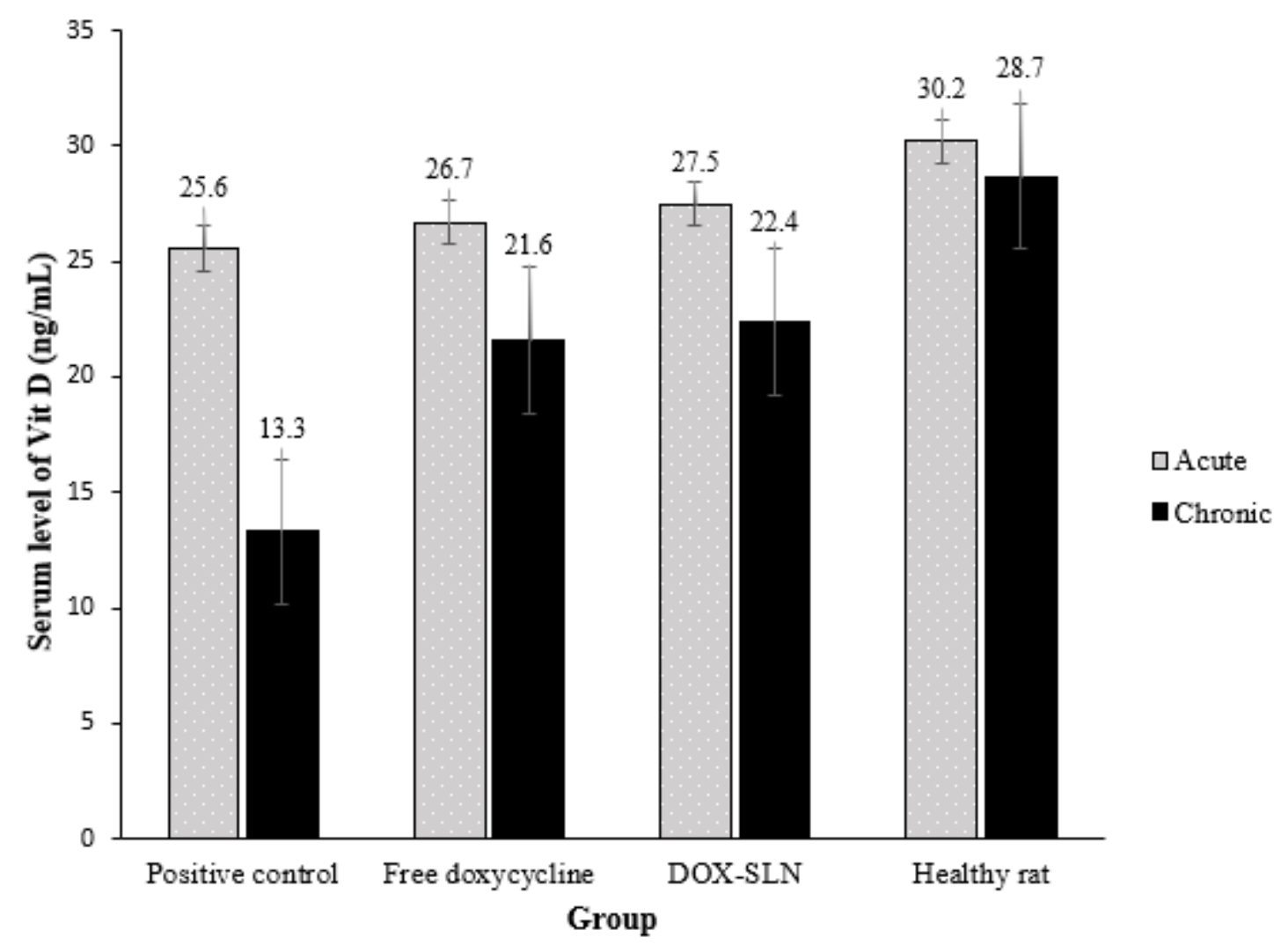

Figure 1

Serum level of Vitamin D in the acute and chronic stage of brucellosis 


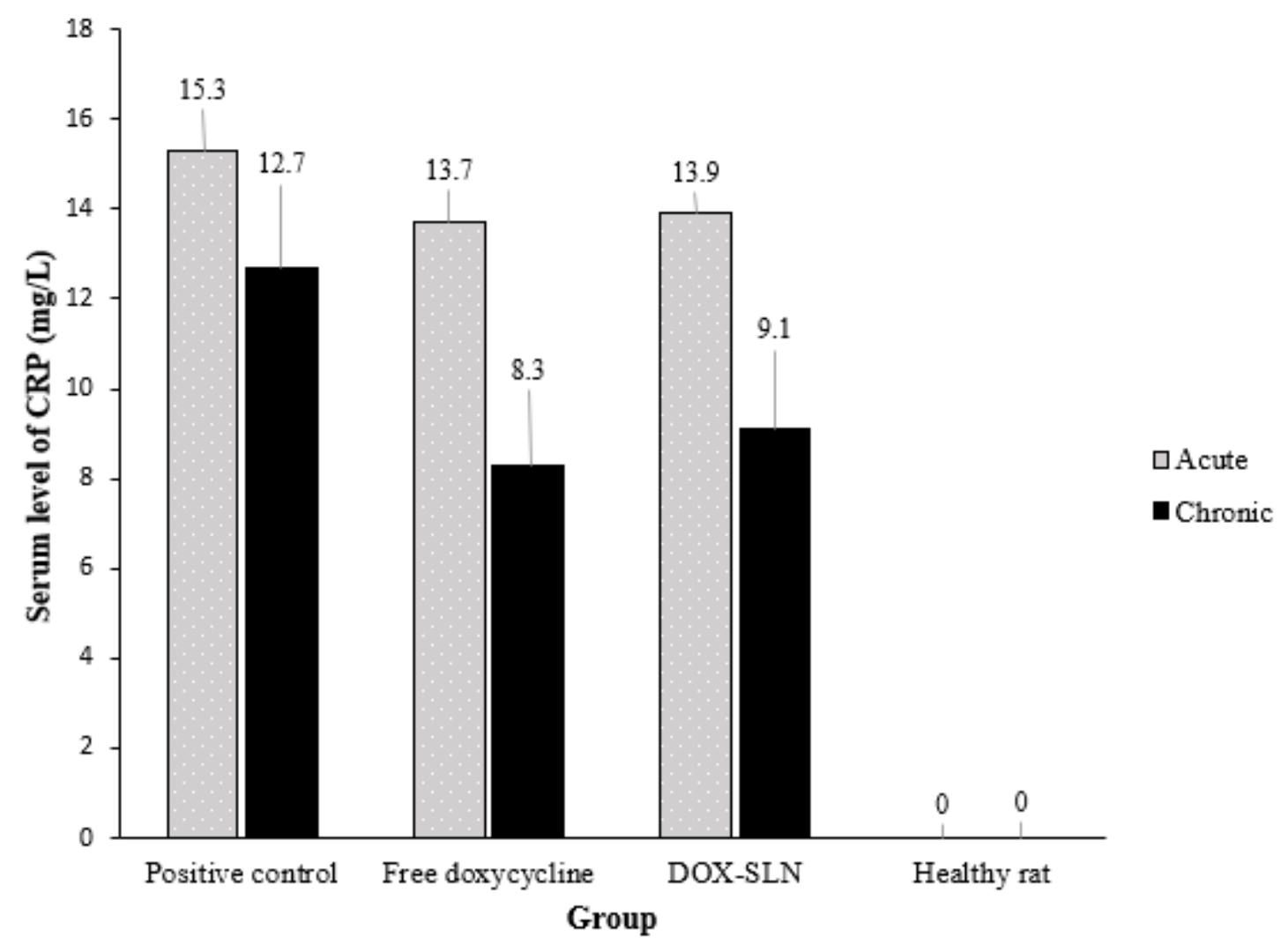

Figure 2

Serum level of CRP in the acute and chronic stage of brucellosis

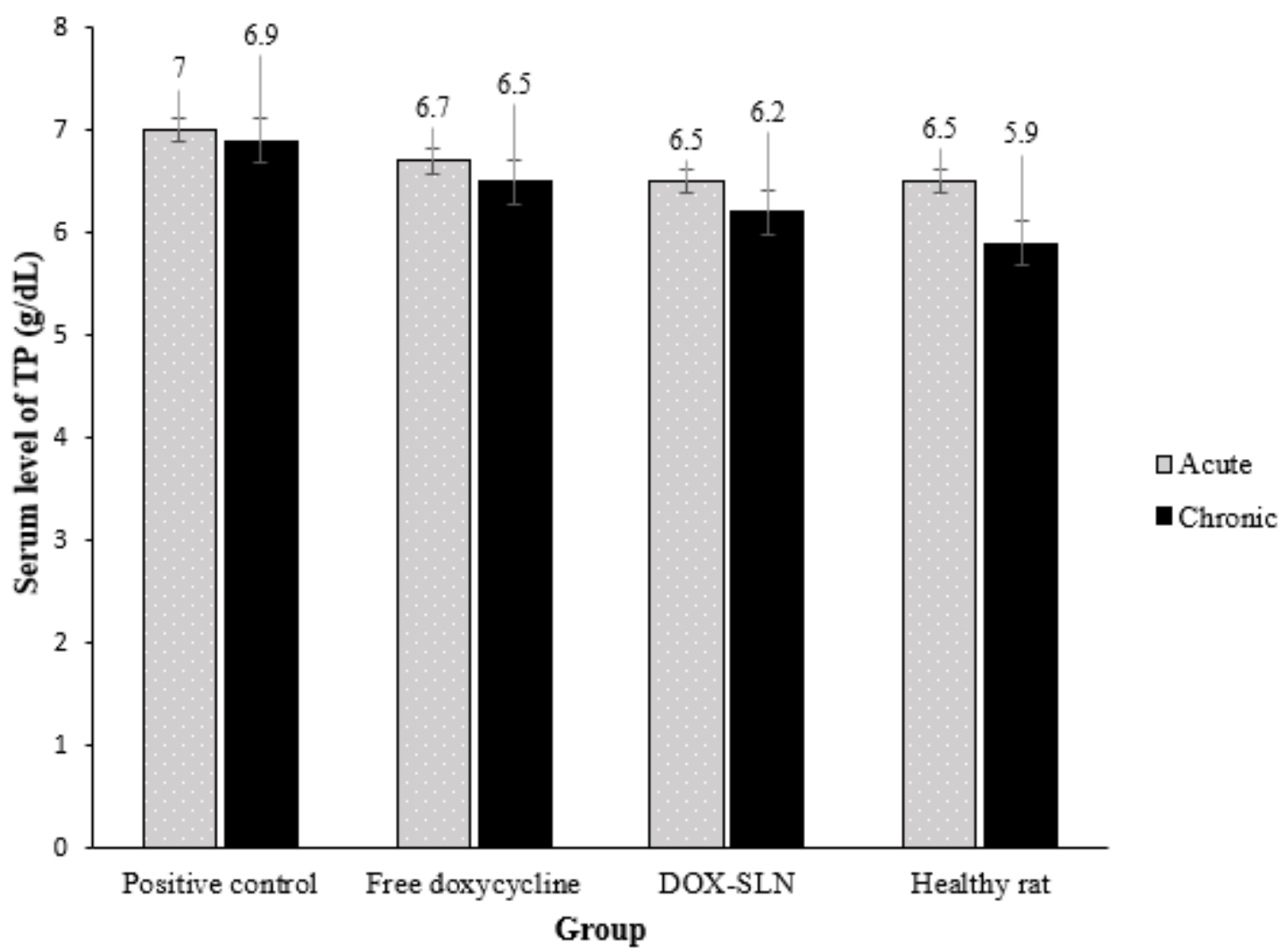


Figure 3

Serum level of total protein in the acute and chronic stage of brucellosis

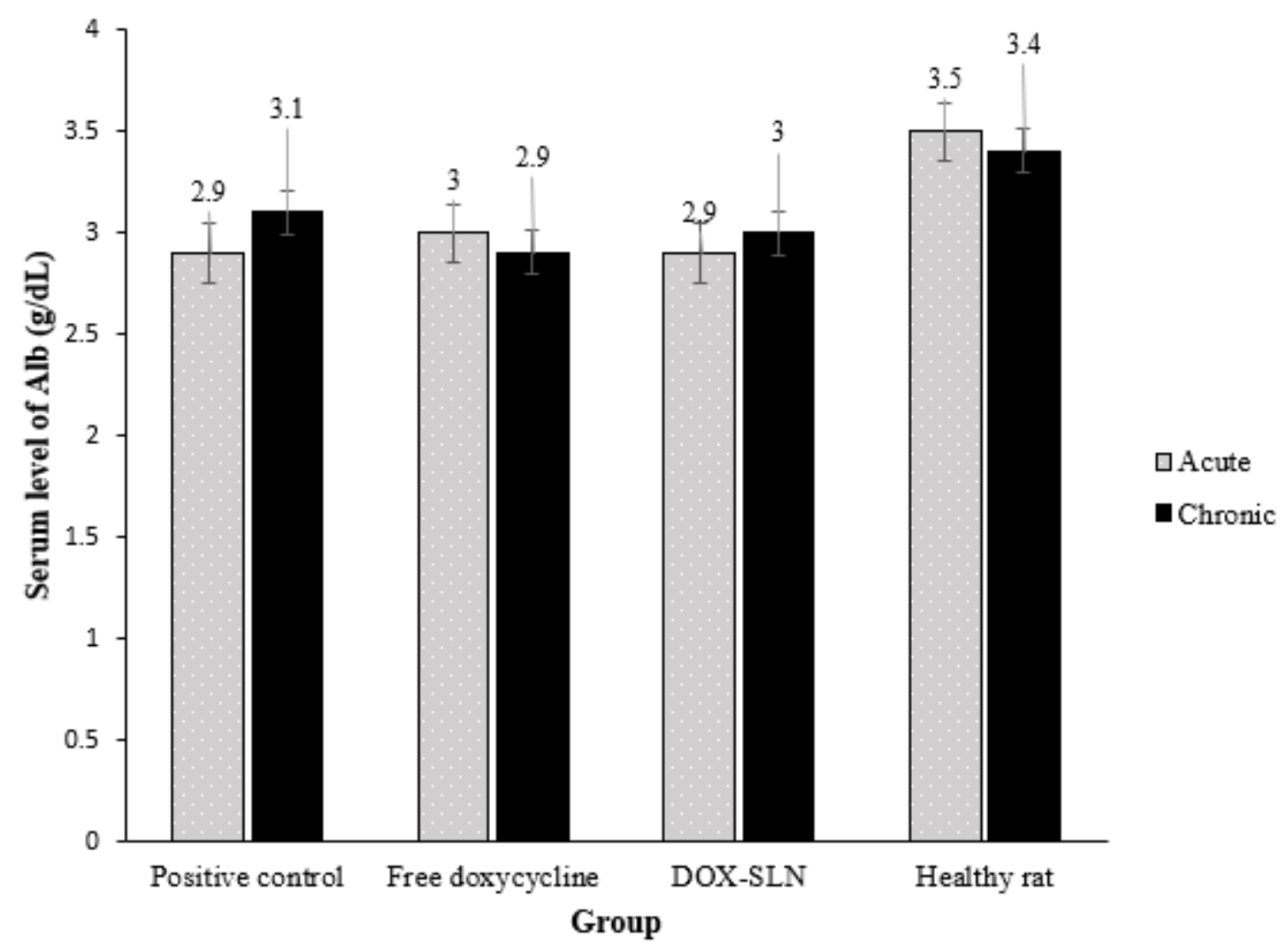

Figure 4

Serum level of Albumin in the acute and chronic stage of brucellosis 


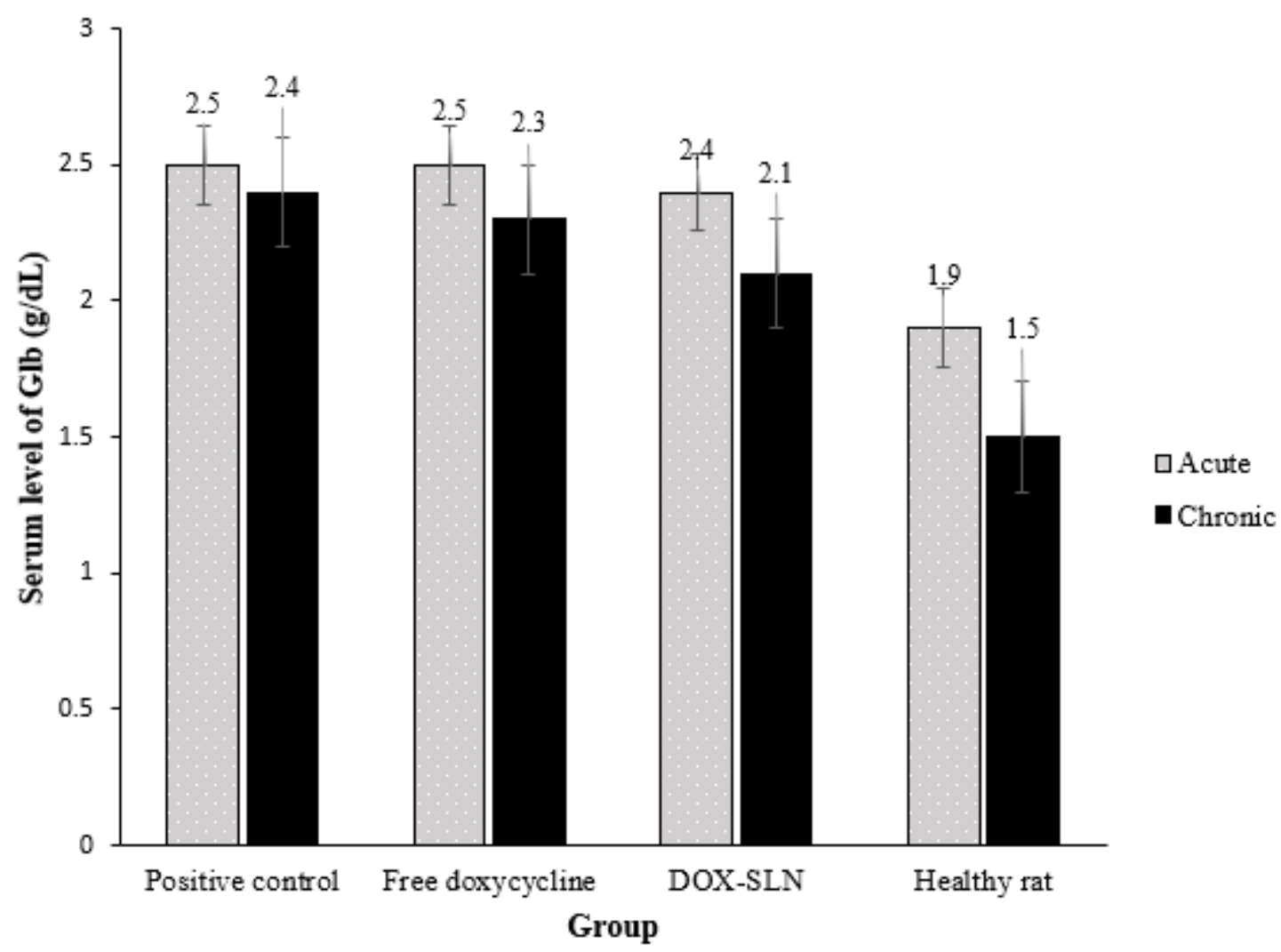

Figure 5

Serum level of Globulin in the acute and chronic stage of brucellosis 